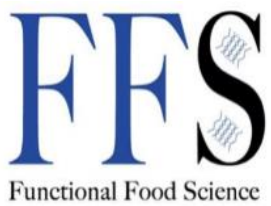

\title{
Phytochemical diversity behind health-promoting effects of traditional Mediterranean foods
}

\author{
Marcello Iriti ${ }^{1,3,4,5^{*}}$, Elena Maria Varoni ${ }^{2,4}$, Sara Vitalini ${ }^{1,3,4}$ \\ ${ }^{1}$ Department of Agricultural and Environmental Sciences, Università degli Studi di Milano, 20133 Milano, Italy; \\ ${ }^{2}$ Department of Biomedical, Surgical and Dental Sciences, Università degli Studi di Milano, 20133 Milano, Italy; \\ ${ }^{3}$ Phytochem Lab, Department of Agricultural and Environmental Sciences, Università degli Studi di Milano, 20133 Milano, \\ Italy; ${ }^{4}$ National Interuniversity Consortium of Materials Science and Technology (INSTM), 50121 Firenze, Italy; ${ }^{5}$ BAT \\ Center-Interuniversity Center for Studies on Bioinspired Agro-Environmental Technology, Università degli Studi di Napoli \\ "Federico II", 80055 Portici (NA), Italy
}

*Corresponding Author: Marcello Iriti, Department of Agricultural and Environmental Sciences, Università degli Studi di Milano, 20133 Milano, Italy

Submission Date: October 11 ${ }^{\text {th }}, 2021$; Acceptance Date: November 16 ${ }^{\text {th }}, 2021$; Publication Date: November $29^{\text {th }}, 2021$

Please cite this article as: Iriti M., Varoni E.M., Vitalini S. Phytochemical diversity behind health-promoting effects of traditional Mediterranean foods. Functional Food Science 2021; 1(11): 67-81. DOI:

https://www.doi.org/10.31989/ffs.v1i11.849

\section{ABSTRACT}

A healthy diet can reduce the risk of non-communicable diseases, including cardiovascular disease and some types of cancer. In general, a diet rich in fruits, vegetables, whole grain cereals, legumes, and nuts, in which products of animal origin are limited, according to the model of the Mediterranean diet, can help prevent the onset of chronic degenerative diseases, together with other lifestyles. This narrative review presents the most representative classes of bioactive phytochemicals and the main Mediterranean foods in which they are present, providing evidence in humans of their health-promoting effects.

Keywords: functional foods, nutraceuticals, plant foods, Mediterranean diet, nutritional therapy, non-communicable diseases, disease prevention

CFFC 2021. This is an Open Access article distributed under the terms of the Creative Commons Attribution 4.0 License (http://creativecommons.org/licenses/by/4.0) 


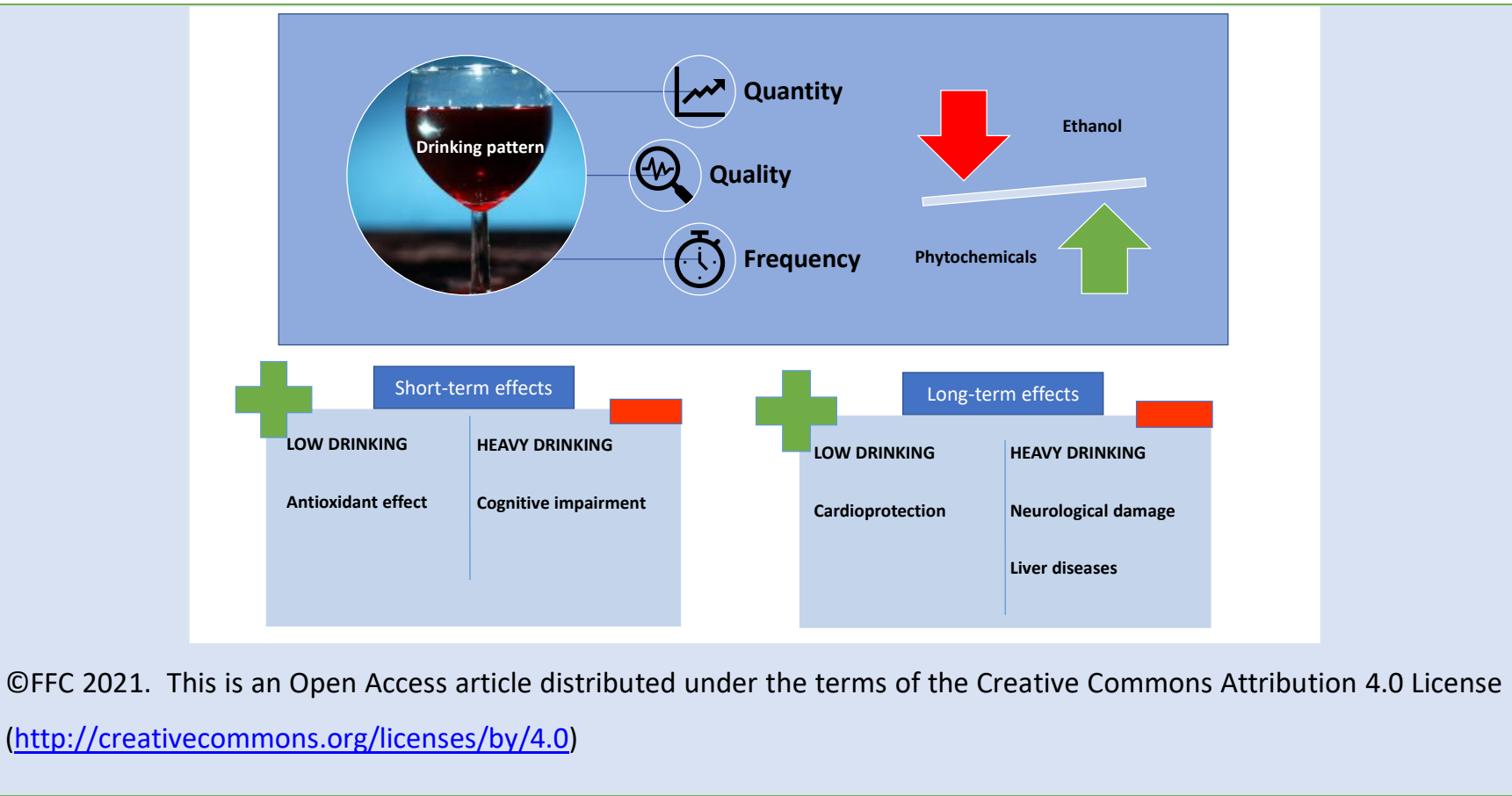

\section{INTRODUCTION}

In the last decades, health benefits of diets rich in plant foods have been emphasized by several observational studies. In addition, preclinical data have pointed out the health-promoting effects of plant foods by virtue of hundreds of bioactive phytochemicals [1]. Mediterranean diet - inscribed in 2013 on the Representative List of the Intangible Cultural Heritage of Humanity - has been considered the archetype of a healthy diet and lifestyle [2].
It includes dietary habits typical of the Mediterranean populations rich in cereals, fruits, vegetables, legumes, nuts, dairy products, seafood, and lean meat (Table 1). Extra virgin olive oil and red wine complete the Mediterranean diet pyramid (Figure 1), since olive tree (Olea europea L.) and grapevine (Vitis vinifera L.) are the most ancient and representative cultivations in the Mediterranean basin. However, wine is an alcoholic beverage and, therefore, it should be consumed consciously [1].

Table 1. Dietary pattern and lifestyles of traditional Mediterranean diet. Adapted from [2].

\section{Dietary habits}

- High consumption of minimally processed, local and seasonal plant food (whole-grain cereals, fresh fruit, cooked and raw vegetables, nuts)

- Daily fat intake ranging from $25 \%$ to $35 \%$ of energy (with saturated fat ranging from $\leq 7 \%$ to $8 \%$ of energy)

- (Extra virgin) olive oil as the main fat used for seasoning, cooking, and baking

- Daily intake of low to moderate amounts of dairy products (mainly low-fat cheese and yogurt)

- Twice-weekly consumption of low to moderate amounts of fish and poultry; up to seven eggs per week

- Fresh fruit as the typical dessert, with sweets containing sugars or honey consumed only a few times per week

- Consumption of red meat only a few times per month

- Regular, low to moderate consumption of wine at main meals; approximately 1-2 glasses per day for men and 1 glass for women (optional)

- Herbs and spices to season food rather than salt or fat

\begin{tabular}{ll}
\hline - Regular daily physical activity & Lifestyles \\
- Enjoy meals with others (family and friends) & \\
\hline
\end{tabular}


Mediterranean Diet Pyramid: a lifestyle for today Guidelines for Adult population
Serving size based on frugality and local habits

Wine in moderation and respecting social beliefs

Sweets $\leq 2 \mathrm{~s}$

Red meat $<2 s$ Processed meat $\leq 1 \mathrm{~s}$

Eggs 2-4s Legumes $\geq 2 s$

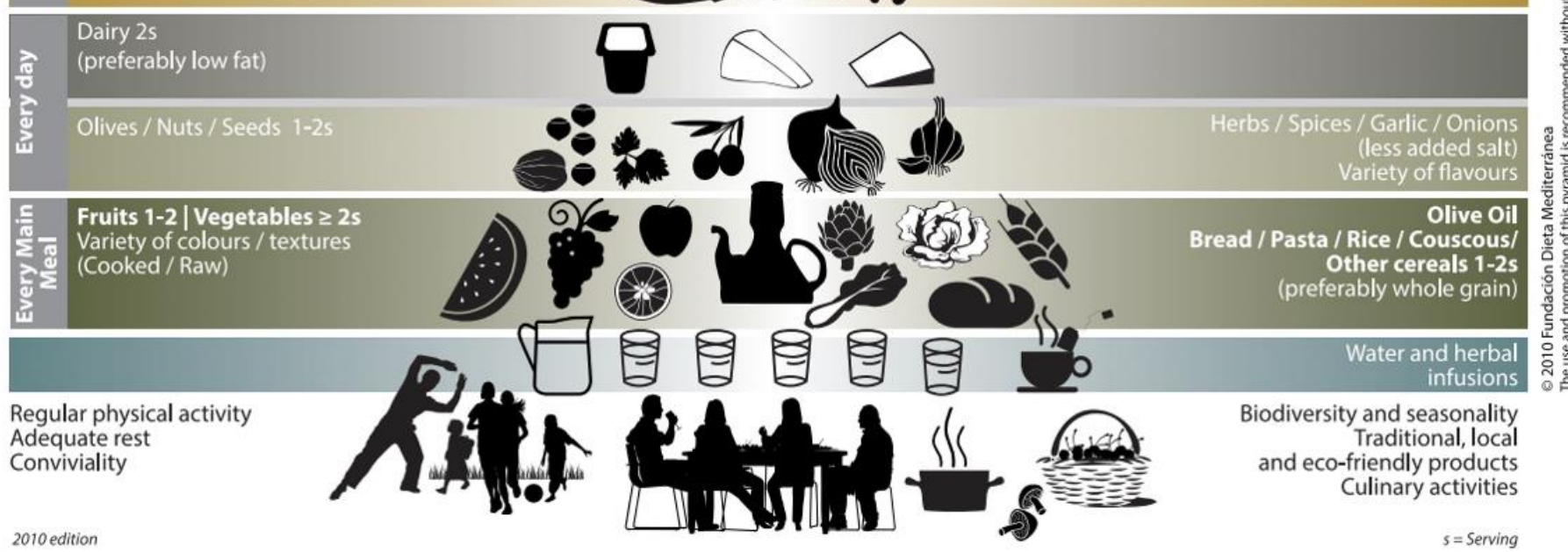

\section{$(8$}

Fundación

Dieta Mediterránea
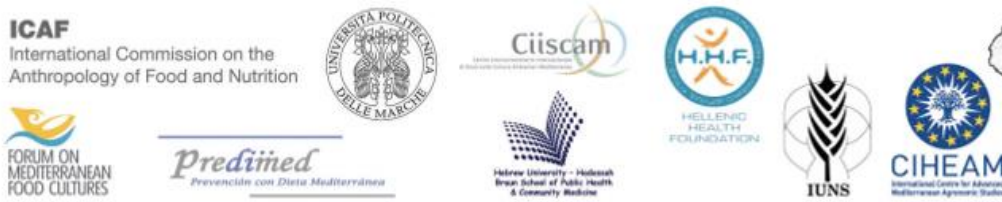

fens

Figure 1. Mediterranean diet pyramid. Fundación Dieta Mediterránea [3].

Plant foods are an important source of micronutrients, i.e., vitamins and minerals, as well as phytochemicals. The latter are secondary metabolites produced by plants as pigments and volatile compounds to confer color and scent to flowers and fruits, hence involved in pollination and seed dispersal. Furthermore, phytochemicals are synthesized ex novo in response to environmental, abiotic, and biotic stressors, due to their antimicrobial, antiviral, antioxidant, and light/UV protectant activities. Very briefly, food and medicinal plants contain hundreds of metabolites arising from different secondary metabolic pathways, such as phenylpropanoids, isoprenoids and alkaloids, each present as aglycone and several glycosides [5].
In the last decades, bioactive phytochemicals and healthy foods have also been defined as nutraceuticals and functional foods. These terms refer to the possibility of some foods and their constituents to improve specific physiological functions of the organism. Therefore, both nutraceuticals and functional foods should not be considered as drugs and, accordingly, a single food or a single compound will hardly improve the health status of the organism. In other words, the complexity of diet can be successful in preventing disease - certainly not in the treatment - and ensuring healthy ageing due to the synergies among different foods and phytochemicals, along with lifestyle including a regular, low to moderate physical activity, and healthy sleeping habits [6]. A large, 
population-based, prospective study showed that a higher adherence to the traditional Mediterranean diet was associated with a significant reduction in total mortality, and, in particular, in mortality due to cardiovascular disease and cancer [7].

Although many reviews on the Mediterranean diet have already been published, the present study focuses on the phytochemical diversity of this dietary pattern, providing a novel perspective. Therefore, this narrative review presents the most representative (and explored) bioactive phytochemicals and the main Mediterranean foods in which they are contained, drawing on the most relevant in human studies mostly on healthy subjects, according to an evidence-based approach.

(Poly)phenols: Probably, polyphenols represent the most explored class of plant secondary metabolites, as a sort of archetype of bioactive phytochemicals (Figure 2).
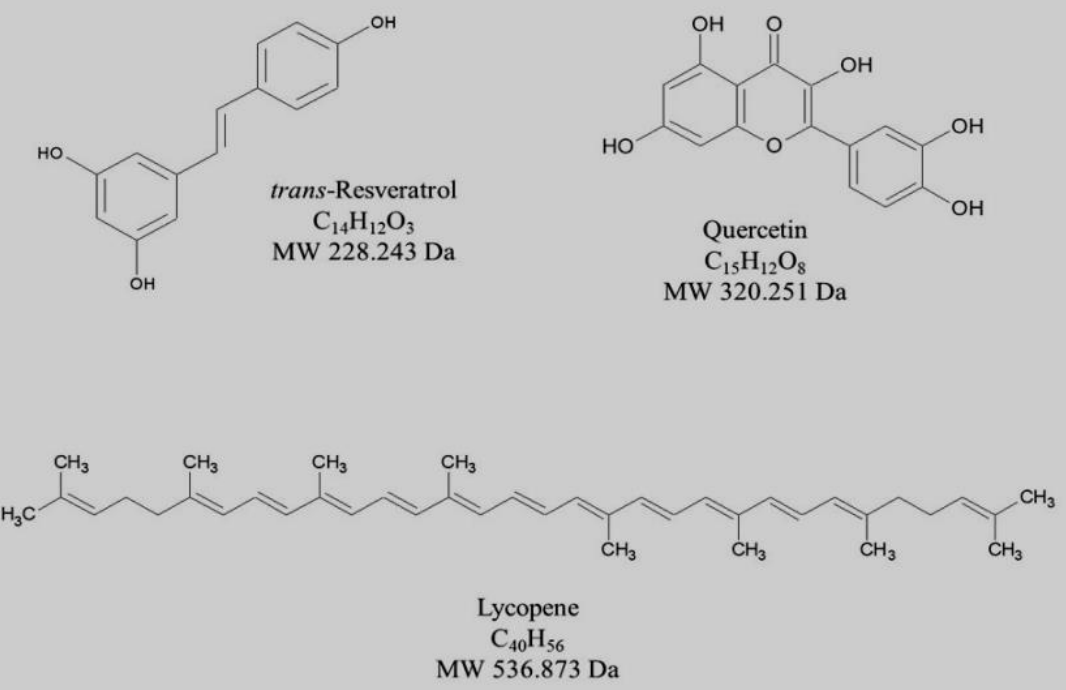
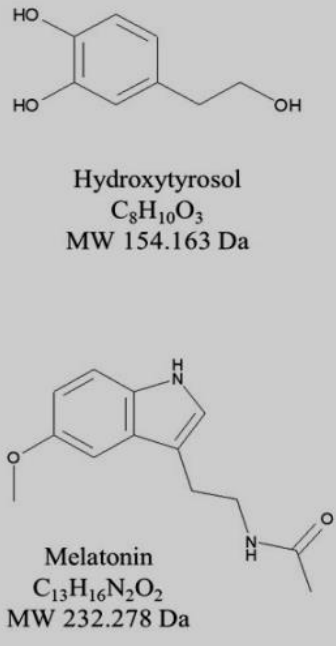

Figure 2. Most investigated bioactive phytochemicals significantly present in the Mediterranean diet. Resveratrol and quercetin are polyphenols (a stilbene and a flavonoid, respectively), hydroxytyrosol is a phenolic compound, lycopene is a carotenoid, and melatonin is an indoleamine. Grape/red wine, olive oil and tomato products are rich in resveratrol/quercetin, hydroxytyrosol and lycopene, respectively. Melatonin is a new element of Mediterranean diet (see the text for details).

They include three main groups, flavonoids (such as quercetin), stilbenes (including resveratrol), and condensed tannins (or proanthocyanidins, oligomeric and polymeric derivatives of flavonoids), investigated for years in plant, food, and nutrition sciences. Polyphenols are phenylalanine derivatives arising from the phenylpropanoid pathway [8]. In particular, resveratrol, present significantly in red wine, can be considered the pioneer of nutraceuticals from the first study, criticized subsequently, revealing that, despite their high saturated fat intake, the French die less of coronary heart disease due to their high consumption of red wine - the so-called French paradox [9]

Now, some studies have corroborated this observation, suggesting that a regular, low to moderate intake of red wine at main meals can have cardioprotective effects probably due to its polyphenol content, even if ethanol itself can be cardioprotective [10-11]. Red wine is a complex food matrix containing hundreds of flavonoids, stilbenes and proanthocyanidins arising from grape, each one with a specific pharmacological target (Table 2). 
Table 2. Mechanisms of grape polyphenol-promoted cardioprotective effects.

\begin{tabular}{|l|l|}
\hline Mechanisms & References \\
\hline - Decrease of oxidative stress & [12] \\
\hline - Inhibition of inflammation and eicosanoid synthesis & [13] \\
\hline - Improvement of endothelial function & [14] \\
\hline - Decrease of LDL & [15] \\
\hline - Increase of HDL & [16] \\
\hline - Inhibition of LDL oxidation & [17] \\
\hline - Inhibition of platelet aggregation and thrombosis & [19] \\
\hline$\bullet$ Improvement of vasorelaxation (eNOS) & [20] \\
\hline - Inhibition of ET-1 & [21] \\
\hline - Improvement of fibrinolysis & [22] \\
\hline \hline
\end{tabular}

LDL, low density lipoproteins; HDL, high density lipoproteins; eNOS, endothelial nitric oxide synthase; ET-1, endothelin-1; VSCM, vascular smooth muscle cells. Adapted from [23].

In other words, this beverage may act as a multitarget cardioprotective agent, with a dose-effect relationship characterized by a J-shaped curve indicating a significant decrease in total mortality with low to moderate drinking versus abstention or heavy drinking [24]. However, as previously introduced, wine is an alcoholic beverage and, therefore, even light drinking could increase the risk of developing some cancers, i.e., breast, colorectal and oral cancer, although many preclinical studies focused on the anticancer activity of resveratrol supplementation [25-26].

To ascertain the health benefits of polyphenols alone, a capsule of red wine extract (300 mg) was administered to healthy volunteers (males and females) and salivary antiradical capacity and total polyphenol content were measured. The extract contained oligomeric proanthocyanidins, flavonoids (quercetin and catechins) and resveratrol. The capsule significantly increased salivary antiradical capacity 30-60 min after drinking compared to baseline and both controls, i.e., subjects drinking a glass $(125 \mathrm{~mL})$ of red wine or water [27].

Nevertheless, foods other than grape and wine are rich in polyphenols and may exert health-promoting effects. In a randomized, controlled, crossover clinical trial, one serving (100 g) of black rice significantly raised the plasma levels of polyphenols and flavonoids in healthy subjects (males and females) at 60-120 min and, correspondingly, the plasma antiradical power at $60 \mathrm{~min}$ after consumption compared to volunteers consuming non-pigmented rice [28]. Anthocyanins, a group of flavonoids, are responsible for the typical color of pigmented rice, including black and red rice cultivars. 
Extra virgin olive oil represents the main source of healthy unsaturated fatty acids in the Mediterranean diet, besides containing bioactive phenolic compounds such as oleuropein, tyrosol and hydroxytyrosol (Figure 2). These olive tree secondary metabolites are not exactly phenylpropanoids, as the polyphenols discussed above: oleuropein is a glycosylated secoiridoid arising from the mevalonate pathway, whereas tyrosol and hydroxytyrosol are generated by the hydrolysis of oleuropein [29].

To evaluate whether the phenolic content of olive oil further benefited plasma lipid levels and lipid oxidative damage compared with monounsaturated acid content, $25 \mathrm{~mL}$ of 3 olive oils were administered daily to healthy male volunteers for 3 weeks, in a randomized, controlled, crossover clinical trial (EUROLIVE Study). Olive oils had low (2.7 mg/kg of olive oil), medium (164 $\mathrm{mg} / \mathrm{kg}$ ), or high (366 mg/kg) phenolic content but were otherwise similar. A linear increase in HDL cholesterol levels was observed for low, medium, and high polyphenol olive oil. Moreover, i) total cholesterol-HDL cholesterol ratio decreased linearly with the phenolic content of the olive oil; ii) triglyceride levels decreased for all olive oils; and iii) oxidative stress markers decreased linearly with increasing phenolic content [30]. The PREDIMED study also demonstrated that olive oil in combination with a Mediterranean dietary pattern improved lipid profile and protected against lipid oxidation, thus reducing the incidence of primary cardiovascular events [31].

The antioxidant effects of hydroxytyrosol were evaluated on body composition, serum metabolites, oxidative stress biomarkers, and expression of genes related to oxidative stress, inflammation, and cardiovascular disease in healthy volunteers in a randomized double-blinded, placebo-controlled crossover clinical study, wherein two gastro-resistant capsules of hydroxytyrosol (15 mg/day) were administered for 3 weeks. Among the parameters investigated, thiol groups, total antioxidant status, superoxide dismutase and plasma levels of hydroxytyrosol increased, whereas nitrites nitrates, and malondialdehyde decreased. Moreover, a significant reduction of body fat mass percentage, suprailiac skinfold, and weight was recorded after hydroxytyrosol treatment [32].

Noteworthy, the scientific opinion of the EFSA has substantiated the health claim ('protection of blood lipids from oxidative stress') concerning the benefits of olive oil phenolic compounds and recommended the daily consumption of at least $5 \mathrm{mg}$ of hydroxytyrosol, tyrosol and oleuropein provided by moderate amounts of extra virgin olive oil (20 g). This dose is responsible for protecting LDL from oxidation (the initial event of atherosclerotic plaque formation), increasing $\mathrm{HDL}$, maintaining a normal blood pressure, and avoiding the pro-inflammatory processes [33]. This is of great interest since it is unique as a health claim that associates a specific dosage of a food bioactive component with cardiovascular risk reduction.

Intriguingly, hydroxytyrosol is also present in foods other than olive oil, such as wine with an average concentration of $2-3 \mathrm{mg} / \mathrm{L} \mathrm{[34],} \mathrm{and} \mathrm{the} \mathrm{tyrosol} \mathrm{to}$ hydroxytyrosol bioconversion was confirmed in subjects at cardiovascular risk after wine intake. In a randomized, controlled, crossover clinical study, individuals received white wine (1 or 2 standard drinks/day for females and males, respectively), white wine plus 1 capsule of tyrosol (25 mg) per drink, and water for 4 weeks. White wine (135 mL) contained $13.5 \mathrm{~g}$ of alcohol, $1.4 \mathrm{mg}$ of tyrosol, 
and $0.2 \mathrm{mg}$ of hydroxytyrosol. The 24-hour urinary recovery of hydroxytyrosol was higher after white wine + tyrosol administration than after other interventions. The same treatment improved endothelial function, increased plasma HDL-cholesterol and antithrombin III, and decreased plasma homocysteine and endothelin 1 [35].

As known, changes in abundance and composition of host gut microbiota are closely related to human health. In this context, the health-promoting effects of polyphenol-rich foods have been partly attributed to the metabolism of polyphenols by gut microbial community. It is estimated that only $5-10 \%$ of the total polyphenol intake is absorbed in the small intestine, whereas the remaining 90-95\% may accumulate in the large intestine. Here, unabsorbed polyphenols are subjected to the enzymatic activity of the colonic microbiota, responsible for the extensive biotransformation and breakdown of polyphenol compounds into absorbable, low molecular weight metabolites that may be responsible for the host health benefits derived from the intake of polyphenolrich foods. In turn, polyphenols and their colonic metabolites can alter or modulate the host gut microbiota, in a kind of inter-dependence between them. Indeed, polyphenol consumption has been reported to maintain the host gut homeostasis, increasing or decreasing both beneficial and harmful microbial species. Exerting both 'prebiotic-like' and antimicrobial effects, polyphenols can stimulate the growth of probiotic bacterial families such as Bifidobacteriaceae and Lactobacillaceae (protectors of the intestinal barrier), inhibiting pathogenic bacteria such as Clostridium spp., Escherichia coli and Helicobacter pylori [36-37].
The typical Mediterranean, (poly)phenol-rich foods can affect the complex gut ecosystem, modifying microbial composition. In a prospective study, red wine intake positively correlated with Faecalibacterium prausnitzii abundance (a butyrate-producing bacterial species with anti-inflammatory properties), and negatively with inflammatory bowel disease; wine consumers also showed higher microbiota diversity [38]. A high adherence to the Mediterranean diet (assessed using the MedDietScore) showed positive correlations with gastrointestinal health, fecal moisture, total bacteria, bifidobacteria: $E$. coli ratio, relative proportion of Bacteroides, Candida albicans and total short chain fatty acids, and negative associations with cultivable $E$. coli and valerate levels [39].

In a randomized, controlled, crossover study, moderate consumption of red wine and dealcoholized red wine for 4 weeks produced an increase in the number of Enterococcus, Prevotella, Bifidobacterium, Bacteroides uniformis, Eggerthella lenta, and Blautia coccoides-Eubacterium rectale groups in healthy male volunteers. In addition, blood pressure and plasma triglycerides, total cholesterol, HDL cholesterol and Creactive protein decreased significantly [40]. In a similar trial in patients suffering from metabolic syndrome, moderate drinking of red wine and dealcoholized red wine for 30 days stimulated the growth of fecal butyrate-producing bacteria (F. prausnitzii and Roseburia spp.) associated with inhibition of metabolic diseases (obesity, diabetes, and inflammation), as well as bifidobacteria and lactobacilli at the expense of lipopolysaccharide producers Escherichia coli and Enterobacter cloacae [41].

The effects of olive oil on gut microbiota were also investigated. In a randomized, controlled, double-blind, 
crossover trial in hypercholesterolemic subjects (males and females), the consumption of olive oil $(25 \mathrm{~mL} /$ day for 3 weeks) enriched with thyme phenolic compounds decreased oxidation of serum LDL. Probably, this cardiometabolic effect could be mediated by increases in bifidobacteria and antioxidant microbial phenolic metabolites (serum protocatechuic acid and fecal hydroxytyrosol) [42].

Non-provitamin A carotenoids: lycopene: Although nonprovitamin A carotenoids (including lycopene, lutein, zeaxanthin, and astaxanthin) do not exhibit vitamin A activity, this group of carotenoids has been associated with a variety of health benefits unrelated to vitamin A functions (Figure 2) [43]. Carotenoids are tetraterpenes arising from acetyl coA via the mevalonate pathway. The Mediterranean diet is probably the most carotenoid-rich diet compared to the European northern diets, due to its high number of fruits and vegetables [44].

Lycopene, the main carotenoid in tomato and, to a higher amount, in processed tomato products (tomato juice, tomato paste, tomato puree and ketchup), has been extensively investigated due to its antioxidant (it is a powerful singlet-oxygen quencher - 100 times more effective than $\alpha$-tocopherol), anti-inflammatory and anticancer properties. The lycopene content of ripe tomatoes ranges from 0.88 to $7.74 \mathrm{mg} / 100 \mathrm{~g}$ [45-46]. The processing (including cooking) of tomato releases lycopene from the food matrix into the lipid phase of the meal, thus increasing its bioavailability, especially when consumed together with dietary fats (such as olive oil - lycopene is highly lipophilic), with consequent increases in plasma lycopene levels. Noteworthy, although $90 \%$ of the lycopene in dietary sources is found in the linear, all-trans conformation, human tissues (particularly liver, adrenal, adipose tissue, testes and prostate) and body fluids contain mainly cis-isomers [47]. The per capita lycopene consumption varies widely, ranging from 0.5 to $20 \mathrm{mg} /$ day depending on the differences in the consumption of raw tomatoes and processed tomato products (richer in lycopene) around the world, whereas physiological levels vary in the range $(0.5-2 \mu \mathrm{M})$ [44]. The EFSA has set an upper limit of 0.5 $\mathrm{mg} / \mathrm{kg}$ body weight/day for the recommended lycopene intake [48].

In healthy subjects (males and females) consuming one meal per day of tomatoes ( $470 \mathrm{~g}$ ) cooked with extra virgin olive oil $(25 \mathrm{~mL})$, both plasma trans-lycopene and cis-lycopene concentrations increased by $82 \%$ and $40 \%$, respectively, after a 5-day dietary intervention. Differently, in individuals consuming tomatoes cooked without olive oil, there was not any significant change in trans-lycopene and only a $15 \%$ increase in cis-lycopene concentrations [49]. Furthermore, it was demonstrated that the preparation of 'sofrito', a typical Mediterranean tomato sauce cooked with olive oil, garlic, and onion, improved the extraction, and modified the bioactive compounds (carotenoids and polyphenols) of the ingredients to more bioaccessible and bioavailable forms, also increasing cis-lycopene formation [50]. Consumption of a single dose of sofrito (240 g) increased plasma carotenoids (including lycopene) and urinary polyphenols in healthy men, while decreasing the inflammatory biomarkers C-reactive protein and tumor necrosis factor- $\alpha$ [51]. A randomized, controlled, parallel clinical trial showed that adherence to Mediterranean diet for six months increased serum lycopene levels and erythrocyte monounsaturated fatty acid in healthy elderly Australians [52]. In a randomized, 
double-blind, placebo controlled, parallel group study, administration of lycopene (7 $\mathrm{mg}$ daily for 2 months) in patients with cardiovascular disease improved by $53 \%$ the endothelium-dependent vasodilatation measured by venous plethysmography as forearm response to intraarterial infusion of acetylcholine [53].

Prostate cancer is perhaps the clinical condition for which lycopene has been most explored. High blood lycopene concentrations have been associated with lower risk of developing prostate cancer [54]. A prospective, case-control study conducted within the Physicians' Health Study showed that aggressive prostate cancer was strongly reduced in subjects with high plasma levels of lycopene [55]. In the EPIC study, the highest quintile of plasma lycopene levels had a $60 \%$ reduced risk for advanced prostate cancer [56]. Many preclinical studies elucidated the lycopene anticancer mechanism that includes reactive oxygens species scavenging, mutagenesis inhibition, modulation of various cell survival pathways, apoptosis induction and cell proliferation inhibition [57].

The effects of lycopene on metabolic syndrome, defined as the co-occurrence of metabolic risk factors that includes insulin resistance, hyperinsulinemia, impaired glucose tolerance, type 2 diabetes, dyslipidemia, and visceral obesity have also been investigated [58-60]. In a dietary intervention trial that enrolled healthy young females, tomato juice administration ( $280 \mathrm{~mL}$ containing $32.5 \mathrm{mg}$ of lycopene,) daily for 2 months significantly increased serum lycopene levels, while decreasing bodyweight, body fat, waist circumference, BMI and total cholesterol [61]. In male individuals diagnosed with metabolic syndrome, tomato juice consumption (100 g containing $2.50 \mathrm{mg}$ of lycopene once a day as refreshment 4 times a week over a period of two months) significantly decreased LDL cholesterol while increasing HDL cholesterol after the intervention period. In addition, compared to the control group, a significant decrease in fasting insulin resistance index was observed in the treatment group [62]. Serum lycopene concentration was inversely correlated with BMI in overweight children [63], as well as to visceral and subcutaneous fat mass, waist circumference, BMI, and C-reactive protein in adults [6465]. In overweight and obese females, the daily intake of tomato juice (330 $\mathrm{mL}$ ) for 20 days increased plasma TAC, erythrocyte antioxidant enzymes (superoxide dismutase, catalase, and glutathione peroxidase) and decreased serum levels of malondialdehyde in the intervention group compared to baseline and the control group [66]. A randomized cross-over clinical trial demonstrated that lycopene-enriched tomato juice $(100 \mathrm{~mL}$ with basil and oregano extract in extra virgin olive oil) administration in obese children for 60 days improved glucose and lipid metabolism through the attenuation of oxidative stress and inflammation, and the regulation of T-lymphocytes mitochondrial metabolism [67]. In a large cross-sectional study, an inverse correlation was confirmed between dietary lycopene intake and gestational diabetes mellitus risk in pregnant women during mid-trimester [68]. Noteworthy, in middle-aged adults (males and females) with moderate obesity, lycopene supplementation ( 7 and $30 \mathrm{mg}$ daily for 1 month) induced dose-dependent changes in the gut microbiota profile with an increase of relative abundance of Bifidobacterium adolescentis and Bifidobacterium longum [69]. 


\section{CONCLUSION}

Adherence to the Mediterranean diet can contribute to reduce the cardiometabolic risk through a multitarget mechanism of action, thus preventing the occurrence of major cardiovascular events by virtue of its typical foods' rich in phenolics and carotenoids, as substantiated by a number of clinical trials. Among these foods, grape/wine, olive oil and tomato (product) polyphenols have been associated with cardioprotection due to their antioxidant, anti-inflammatory, antiatherosclerosis, vasodilating, antithrombotic and prebiotic effects. In particular, the knowledge of the complex relationships between phytochemicals and gut microbiota is still in the early stages of research, and this study area should be greatly potentiated in the near future. However, a causal relationship between Mediterranean diet and cardioprotection (and metabolic syndrome) is far from fully established. The same is true, even more so, for the anticancer effects, although some evidence suggests a chemopreventive potential of Mediterranean diet.

Of course, resveratrol, hydroxytyrosol and lycopene are not the only bioactive phytochemicals present in the Mediterranean diet, as well as wine, olive oil and tomato are not the only foods. On the contrary, chemical and food diversities are typical traits of this dietary style. Intriguingly, it has been suggested that melatonin (Figure 2), significantly present in Mediterranean foods, can represent a new element to further corroborate the health-promoting effects of Mediterranean diet [70-73]. Therefore, the health benefits of Mediterranean diet do not rely on a single compound or food, but rather on the synergistic effects of several components: phytochemicals, foods and, above all, dishes. Indeed, food preparation according to the Mediterranean recipes can potentiate the health effects of the single components, also improving the oral bioavailability of some phytochemicals, as in the case of sofrito, spaghetti with tomato sauce and pizza, the latter inscribed in 2017 on the Representative List of the Intangible Cultural Heritage of Humanity [74]. In this view, it would seem that Mediterranean dishes and recipes represent the real strength, even if Mediterranean lifestyle consists of many sociocultural aspects relevant in terms of healthy aging and life expectancy.

Abbreviations: BMI: body mass index, EFSA: European Food Safety Authority, ET-1: endothelin-1, eNOS: endothelial nitric oxide synthase, EPIC: European Prospective Investigation into Cancer and Nutrition, HDL: high density lipoproteins, LDL: low density lipoproteins, TAC: total antioxidant capacity, VSCM: vascular smooth muscle cells.

Competing interest: The authors have no financial interests or conflicts of interest.

Authors' contribution: All authors contributed equally to the review article.

Acknowledgments: Authors acknowledge all the people who have handed down the traditional knowledge and uses of food and medicinal plants. 


\section{REFERENCES}

1. Iriti $M$, Vitalini S. Health-promoting effects of traditional Mediterranean diets-A review. Pol J Food Nutr Sci. 2012 62.https://doi.org/10.2478/v10222-011-0047-z

2. Mediterranean Diet [https://ich.unesco.org/en/RL/mediterranean-diet-00884] Retrieved November 23, 2021.

3. The Mediterranean Diet pyramid has adapted to the new way of life.

http://www.mediterradiet.org/nutrition/mediterranean di et_pyramid) Retrieved November 23, 2021.

4. Iriti $M$, Varoni EM, Vitalini S. Healthy diets and modifiable risk factors for non-communicable diseases - The European perspective. Foods. 2020; 9:940. https://doi.org/10.3390/foods9070940

5. Iriti M, Faoro F. Chemical diversity and defence metabolism: how plants cope with pathogens and ozone pollution. Int J Mol Sci. 2009a; 10:3371-3399.

https://doi.org/10.3390/ijms10083371

6. Moreira P, Santos S, Padrão P, Cordeiro T, Bessa M, Valente H, Barros R, Teixeira V, Mitchell V, Lopes C, Moreira A. Food patterns according to sociodemographics, physical activity, sleeping and obesity in Portuguese children. Int J Environ Res Public Health. 2010; 7:1121-1138.

https://doi.org/10.3390/ijerph7031121

7. Trichopoulou A, Costacou T, Bamia C, Trichopoulos D. Adherence to a Mediterranean diet and survival in a Greek population. N Engl J Med. 2003; 348:2599-2608. https://doi.org/10.1056/NEJMoa025039

8. Iriti M, Faoro F. Grape phytochemicals: a bouquet of old and new nutraceuticals for human health. Med Hypotheses. 2006; 67:833-838.

https://doi.org/10.1016/j.mehy.2006.03.049

9. Iriti M, Faoro F. Bioactivity of grape chemicals for human health. Nat Prod Commun. 2009b; 4.

10. Iriti M, Varoni EM. Cardioprotective effects of moderate red wine consumption: Polyphenols vs. ethanol. J Appl Biomed. 2014; 12:193-202

https://doi.org/10.1016/j.jab.2014.09.003

11. Xi B, Veeranki SP, Zhao M, Ma C, Yan Y, Mi J. Relationship of alcohol consumption to all-cause, cardiovascular, and cancer-related mortality in U.S. adults. J Am Coll Cardiol. 2017; 70:913. https://doi.org/10.1016/j.jacc.2017.06.054
12. Martinez J, Moreno JJ. Effect of resveratrol, a natural polyphenolic compound, on reactive oxygen species and prostaglandin production. Biochem Pharmacol. 2000; 59:865-870.https://doi.org/10.1016/S0006-2952(99)00380$\underline{9}$

13. Csiszar A, Smith K, Labinskyy N, Orosz Z, Rivera A, Ungvari Z. Resveratrol attenuates TNF-alpha-induced activation of coronary arterial endothelial cells: role of NF-kappaB inhibition. Am. J Physiol Heart Circul Physiol. 2006; 291:1694-1699.

https://doi.org/10.1152/ajpheart.00340.2006

14. Perez-Vizcaino F, Duarte J, Andriantsitohaina R. Endothelial function and cardiovascular disease: effects of quercetin and wine polyphenols. Free Rad Res. 2006; 40:1054-1065. https://doi.org/10.1080/10715760600823128

15. Zern TL, Wood RJ, Greene C, West KL, Liu Y, Aggarwal D, Shachter NS, Fernández ML. Grape polyphenols exert a cardioprotective effect in pre- and postmenopausal women by lowering plasma lipids and reducing oxidative stress. J Nutr. 2005; 135:1911-1917. https://doi.org/10.1093/jn/135.8.1911

16. Castilla P, Echarri R, Dávalos A, Cerrato F, Ortega H, Teruel JL, Lucas MF, Gómez-Coronado D, Ortuño J, Lasunción MA. Concentrated red grape juice exerts antioxidant, hypolipidemic, and antiinflammatory effects in both hemodialysis patients and healthy subjects. Am J Clin Nutr. 2006; 84:252-262. https://doi.org/10.1093/ajcn/84.1.252

17. Stein JH, Keevil JG, Wiebe DA, Aeschlimann S, Folts JD. Purple grape juice improves endothelial function and reduces the susceptibility of LDL cholesterol to oxidation in patients with coronary artery disease. Circulation. 1999; 100:1050-1055. https://doi.org/10.1161/01.cir.100.10.1050

18. Shanmuganayagam D, Beahm MR, Osman HE, Krueger GG, Reed JD, Folts JD. Grape seed and grape skin extracts elicit a greater anti-platelet effect when used in combination than when used individually in dogs and humans. J Nutr. 2002; 132:3592-3598.

https://doi.org/10.1093/jn/132.12.3592

19. Wallerath T, Deckert G, Ternes T, Anderson H, Li H, Witte K, Forstermann U. Resveratrol, a polyphenolic phytoalexin present in red wine, enhances expression and activity of endothelial nitric oxide synthase. Circulation. 2002; 106:1652-1658.

https://doi.org/10.1161/01.cir.0000029925.18593.5c 
20. Corder R, Douthwaite JA, Lees DM, Khan NQ, Viseu Dos Santos AC, Wood EG, Carrier MJ. Endothelin-1 synthesis reduced by red wine. Nature. 2001; 414:863-864. https://doi.org/10.1038/414863a

21. Abou-Agag LH, Aikens ML, Tabengwa EM. Polyphenolics increase t-PA and u-PA gene transcription in cultured human endothelial cells. Alcohl Clin Exp Res. 2001; 25:155162.

22. Araim O, Ballantyne J, Waterhouse A, Sumpio BE. Inhibition of vascular smooth muscle cell proliferation with red wine and red wine polyphenols. J Vasc Surg. 2002; 35:1226-1232. https://doi.org/10.1067/mva.2002.124358

23. Iriti $\mathrm{M}$, Vitalini $\mathrm{S}$. Chemical diversity of grape products, a complex blend of bioactive secondary metabolites. J Nat Prod. 2011; 1:71-74. https://doi.org/10.2174/2210315511101010071

24. de Gaetano G, Costanzo S. Alcohol and health: Praise of the J curves. J Am Coll Cardiol. 2017; 70:923-925. https://doi.org/10.1016/j.jacc.2017.07.710

25. Varoni EM, Lodi G, Iriti M. Ethanol versus phytochemicals in wine: oral cancer risk in a light drinking perspective. Int J Mol Sci. 2015; 16:17029-17047. https://doi.org/10.3390/ijms160817029

26. Varoni EM, Lo Faro AF, Sharifi-Rad J, Iriti M. Anticancer molecular mechanisms of resveratrol. Front Nutr. 2016; 3:8. https://doi.org/10.3389/fnut.2016.00008

27. Varoni EM, Vitalini S, Contino D, Lodi G, Simonetti P, Gardana C, Sardella A, Carrassi A, Iriti M. Effects of red wine intake on human salivary antiradical capacity and total polyphenol content. Food Chem Toxicol. 2013; 58:289-294. https://doi.org/10.1016/j.fct.2013.04.047

28. Vitalini S, Sardella A, Fracassetti D, Secli R, Tirelli A, Lodi G, Carrassi A, Varoni EM, Iriti M. Polyphenol bioavailability and plasma antiradical capacity in healthy subjects after acute intake of pigmented rice: A crossover randomized controlled clinical trial. J Clin Med. 2020; 9:3209.

https://doi.org/10.3390/jcm9103209

29. Nediani C, Ruzzolini J, Romani A, Calorini L. Oleuropein, a bioactive compound from Olea europaea L., as a potential preventive and therapeutic agent in non-communicable diseases. Antioxidants. 2019; 8:578.

https://doi.org/10.3390/antiox8120578

30. Covas MI, Nyyssönen K, Poulsen HE, Kaikkonen J, Zunft HJ, Kiesewetter H, Gaddi A, de la Torre R, Mursu J, Bäumler H,
Nascetti S, Salonen JT, Fitó M, Virtanen J, Marrugat J; EUROLIVE Study Group. The effect of polyphenols in olive oil on heart disease risk factors: a randomized trial. Ann Intern Med. 2006; 145:333-341.

https://doi.org/10.7326/0003-4819-145-5-200609050$\underline{00006}$

31. Estruch R, Ros E, Salas-Salvadó J, Covas MI, Corella D, Arós F, Gómez-Gracia E, Ruiz-Gutiérrez V, Fiol M, Lapetra J, Lamuela-Raventos RM, Serra-Majem L, Pintó X, Basora J, Muñoz MA, Sorlí JV, Martínez JA, Fitó M, Gea A, Hernán MA, Martínez-González MA; PREDIMED Study Investigators. Primary prevention of cardiovascular disease with a Mediterranean diet supplemented with extra-virgin olive oil or nuts. N Engl J Med. 2018; 378:e34. https://doi.org/10.1056/NEJMoa1800389

32. Colica C, Di Renzo L, Trombetta D, Smeriglio A, Bernardini S, Cioccoloni G, Costa de Miranda R, Gualtieri P, Sinibaldi Salimei P, De Lorenzo A. Antioxidant effects of a hydroxytyrosol-based pharmaceutical formulation on body composition, metabolic state, and gene expression: a randomized double-blinded, placebo-controlled crossover trial. Oxid Med Cell Longev. 2017; 2473495.

https://doi.org/10.1155/2017/2473495

33. European Food Safety Authority (EFSA) Panel on Dietetic Products, Nutrition and Allergies (NDA). Scientific opinion on the substantiation of health claims related to polyphenols in olive and protection of LDL particles from oxidative damage (ID 1333, 1638, 1639, 1696, 2865), maintenance of normal blood HDL cholesterol concentrations (ID 1639), maintenance of normal blood pressure (ID 3781), "anti-inflammatory properties"(ID 1882), "contributes to the upper respiratory tract health"(ID 3468), "can help to maintain a normal function of gastrointestinal tract"(3779), and "contributes to body defences against external agents" (ID 3467) pursuant to article 13(1) of regulation (EC) no 1924/2006. EFSA J. 2011; 9:2033-2058. https://doi.org/10.2903/j.efsa.2011.2033

34. Robles-Almazan M, Pulido-Moran M, Moreno-Fernandez J, Ramirez-Tortosa C, Rodriguez-Garcia C, Quiles JL, RamirezTortosa M. Hydroxytyrosol: Bioavailability, toxicity, and clinical applications. Food Res Int. 2018; 105:654-667. https://doi.org/10.1016/j.foodres.2017.11.053

35. Boronat A, Mateus J, Soldevila-Domenech N, Guerra M, Rodríguez-Morató J, Varon C, Muñoz D, Barbosa F, Morales 
JC, Gaedigk A, Langohr K, Covas MI, Pérez-Mañá C, Fitó M, Tyndale RF, de la Torre R. Cardiovascular benefits of tyrosol and its endogenous conversion into hydroxytyrosol in humans. A randomized, controlled trial. Free Radic Biol Med. 2019; 143:471-481.

https://doi.org/10.1016/j.freeradbiomed.2019.08.032

36. Moorthy M, Chaiyakunapruk N, Jacob SA, Palanisamy UD. Prebiotic potential of polyphenols, its effect on gut microbiota and anthropometric/clinical markers: A systematic review of randomised controlled trials. Trends Food Sci Technol. 2020; 99:634-649.

\section{https://doi.org/10.1016/j.tifs.2020.03.036}

37. Aravind $\mathrm{SM}$, Wichienchot $\mathrm{S}$, Tsao R, Ramakrishnan $\mathrm{S}$, Chakkaravarthi S. Role of dietary polyphenols on gut microbiota, their metabolites and health benefits. Food Res Int. 2021; 142:110189. https://doi.org/10.1016/j.foodres.2021.110189

38. Zhernakova A, Kurilshikov A, Bonder MJ, Tigchelaar EF, Schirmer M, Vatanen T, Mujagic Z, Vila AV, Falony G, VieiraSilva S, Wang J, Imhann F, Brandsma E, Jankipersadsing SA, Joossens $M$, Cenit MC, Deelen $P$, Swertz MA; LifeLines cohort study, Weersma RK, Feskens EJ, Netea MG, Gevers D, Jonkers D, Franke L, Aulchenko YS, Huttenhower C, Raes J, Hofker MH, Xavier RJ, Wijmenga C, Fu J. Population-based metagenomics analysis reveals markers for gut microbiome composition and diversity. Science. 2016; 352:565-569. https://doi.org/10.1126/science.aad3369

39. Mitsou EK, Kakali A, Antonopoulou S, Mountzouris KC, Yannakoulia M, Panagiotakos DB, Kyriacou A. Adherence to the Mediterranean diet is associated with the gut microbiota pattern and gastrointestinal characteristics in an adult population. Br J Nutr. 2017; 117:1645-1655.

https://doi.org/10.1017/S0007114517001593

40. Queipo-Ortuño Ml, Boto-Ordóñez M, Murri M, GomezZumaquero JM, Clemente-Postigo M, Estruch R, Cardona Diaz F, Andrés-Lacueva C, Tinahones FJ. Influence of red wine polyphenols and ethanol on the gut microbiota ecology and biochemical biomarkers. Am J Clin Nutr. 2012; 95:1323-1334. https://doi.org/10.3945/ajcn.111.027847

41. Moreno-Indias I, Sánchez-Alcoholado L, Pérez-Martínez P, AndrésLacueva C, Cardona F, Tinahones F, Queipo-Ortuño MI. Red wine polyphenols modulate fecal microbiota and reduce markers of the metabolic syndrome in obese patients. Food Funct. 2016; 7:1775-1787. https://doi.org/10.1039/c5fo00886g

42. Martín-Peláez S, Mosele JI, Pizarro N, Farràs M, de la Torre R, Subirana I, Pérez-Cano FJ, Castañer O, Solà R, FernandezCastillejo S, Heredia S, Farré M, Motilva MJ, Fitó M. Effect of virgin olive oil and thyme phenolic compounds on blood lipid profile: implications of human gut microbiota. Eur J Nutr. 2017; 56:119-131. https://doi.org/10.1007/s00394-015-1063-2

43. Bohn T. Bioavailability of non-provitamin A carotenoids. Curr Nutr Food Sci. 2008; 4:240-258.

44. Marhuenda-Muñoz M, Hurtado-Barroso S, TresserraRimbau A, Lamuela-Raventós RM. A review of factors that affect carotenoid concentrations in human plasma: differences between Mediterranean and Northern diets. Eur J Clin Nutr. 2019; 72:18-25. https://doi.org/10.1038/s41430-018-0305-9

45. Przybylska S. Lycopene-a bioactive carotenoid offering multiple health benefits: a review. Int J Food Sci Technol. 2020; 55:11-32. https://doi.org/10.1111/ijfs.14260

46. Song X, Luo Y, Ma L, Hu X, Simal-Gandara J, Wang LS, Bajpai VK, Xiao J, Chen F. Recent trends and advances in the epidemiology, synergism, and delivery system of lycopene as an anti-cancer agent. Semin Cancer Biol. 2021; 73:331346. https://doi.org/10.1016/j.semcancer.2021.03.028

47. Caseiro M, Ascenso A, Costa A, Creagh-Flynn J, Johnson M, Simões S. Lycopene in human health. LWT-Food Sci Technol. 2020; 127:109323. 
48. European Food Safety Authority (EFSA). Use of lycopene as a food colour - Scientific opinion of the panel on food additives, flavourings, processing aids and materials in contact with food. EFSA J. 2008; 6:674.

\section{https://doi.org/10.2903/j.efsa.2008.674}

49. Fielding JM, Rowley KG, Cooper P, O'Dea K. Increases in plasma lycopene concentration after consumption of tomatoes cooked with olive oil. Asia Pac J Clin Nutr. 2005; $14: 131-136$

50. Rinaldi de Alvarenga JF, Quifer-Rada P, Francetto Juliano F, Hurtado-Barroso S, Illan M, Torrado-Prat X, LamuelaRaventós RM. Using extra virgin olive oil to cook vegetables enhances polyphenol and carotenoid extractability: A study applying the sofrito technique. Molecules. 2019; 24:1555. https://doi.org/10.3390/molecules24081555

51. Hurtado-Barroso $S$, Martínez-Huélamo $M$, Rinaldi de Alvarenga JF, Quifer-Rada P, Vallverdú-Queralt A, PérezFernández S, Lamuela-Raventós RM. Acute effect of a single dose of tomato sofrito on plasmatic inflammatory biomarkers in healthy men. Nutrients, 2019; 11:851. https://doi.org/10.3390/nu11040851

52. Davis C, Hodgson J, Bryan J, Garg M, Woodman R, Murphy K. Older Australians can achieve high adherence to the Mediterranean diet during a 6 month randomised intervention; results from the Medley Study. Nutrients. 2017; 9:534. https://doi.org/10.3390/nu9060534

53. Gajendragadkar PR, Hubsch A, Mäki-Petäjä KM, Serg $M$, Wilkinson IB, Cheriyan J. Effects of oral lycopene supplementation on vascular function in patients with cardiovascular disease and healthy volunteers: a randomised controlled trial. PloS One, 2014; 9:e99070.

https://doi.org/10.1371/journal.pone.0099070

54. Capurso C, Vendemiale G. The Mediterranean diet reduces the risk and mortality of the prostate cancer: A narrative review. Front Nutr. 2017; 4:38.

https://doi.org/10.3389/fnut.2017.00038
55. Gann PH, Ma J, Giovannucci E, Willett W, Sacks FM, Hennekens $\mathrm{CH}$, Stampfer MJ. Lower prostate cancer risk in men with elevated plasma lycopene levels: results of a prospective analysis. Cancer Res. 1999; 59:1225-1230.

56. Key TJ, Appleby PN, Allen NE, Travis RC, Roddam AW, Jenab M, Egevad L, Tjønneland A, Johnsen NF, Overvad K, Linseisen J, Rohrmann S, Boeing H, Pischon T, Psaltopoulou T, Trichopoulou A, Trichopoulos D, Palli D, Vineis P, Tumino R, Berrino F, Kiemeney L, Bueno-de-Mesquita HB, Quirós JR, González CA, Martinez C, Larrañaga N, Chirlaque MD, Ardanaz E, Stattin P, Hallmans G, Khaw KT, Bingham S, Slimani N, Ferrari P, Rinaldi S, Riboli E. Plasma carotenoids, retinol, and tocopherols and the risk of prostate cancer in the European Prospective Investigation into Cancer and Nutrition study. Am J Clin Nutr. 2007; 86:672-681.

https://doi.org/10.1093/ajcn/86.3.672

57. Mirahmadi M, Azimi-Hashemi S, Saburi E, Kamali H, Pishbing M, Hadizadeh F. Potential inhibitory effect of lycopene on prostate cancer. Biomed Pharmacother. 2020; 129:110459

58. Finicelli M, Squillaro T, Di Cristo F, Di Salle A, Melone MAB, Galderisi U, Peluso G. Metabolic syndrome, Mediterranean diet, and polyphenols: Evidence and perspectives. J Cell Physiol. 2019; 234:5807-5826.

https://doi.org/10.1002/jcp.27506

59. Senkus KE, Tan L, Crowe-White KM. Lycopene and metabolic syndrome: A systematic review of the literature. Adv Nutr. 2019; 10:19-29.

https://doi.org/10.1093/advances/nmy069

60. Zhu R, Chen B, Bai Y, Miao T, Rui L, Zhang H, Xia B, Li Y, Gao S, Wang XD, Zhang D. Lycopene in protection against obesity and diabetes: A mechanistic review. Pharmacol Res. 2020; 159:104966.

https://doi.org/10.1016/j.phrs.2020.104966

61. Li YF, Chang YY, Huang HC, Wu YC, Yang MD, Chao PM. Tomato juice supplementation in young women reduces 
inflammatory adipokine levels independently of body fat reduction. Nutrition. 2015; 31:691-696.

https://doi.org/10.1016/j.nut.2014.11.008

62. Tsitsimpikou C, Tsarouhas K, Kioukia-Fougia N, Skondra C, Fragkiadaki P, Papalexis P, Stamatopoulos P, Kaplanis I, Hayes AW, Tsatsakis A, Rentoukas E. Dietary supplementation with tomato-juice in patients with metabolic syndrome: a suggestion to alleviate detrimental clinical factors. Food Chem Toxicol. 2014; 74:9-13. https://doi.org/10.1016/j.fct.2014.08.014

63. Park E. Birth weight was negatively correlated with plasma ghrelin, insulin resistance, and coenzyme Q10 levels in overweight children. Nutr Res Pract. 2010; 4:311-316. https://doi.org/10.4162/nrp.2010.4.4.311

64. Sluijs I, Beulens JW, Grobbee DE, van der Schouw YT. Dietary carotenoid intake is associated with lower prevalence of metabolic syndrome in middle-aged and elderly men. J Nutr. 2009; 139:987-92.

65. Harari A, Coster ACF, Jenkins A, Xu A, Greenfield JR, Harats D, Shaish A, Samocha-Bonet D. Obesity and insulin resistance are inversely associated with serum and adipose tissue carotenoid concentrations in adults. J Nutr. 2020; 150:38-46. https://doi.org/10.1093/jn/nxz184

66. Ghavipour M, Sotoudeh G, Ghorbani M. Tomato juice consumption improves blood antioxidative biomarkers in overweight and obese females. Clin Nutr. 2015; 34:805-809. https://doi.org/10.1016/j.clnu.2014.10.012

67. Negri R, Trinchese G, Carbone F, Caprio MG, Stanzione G, di Scala C, Micillo T, Perna F, Tarotto L, Gelzo M, Cavaliere G, Spagnuolo MI, Corso G, Mattace Raso G, Matarese G, Mollica MP, Greco L, lorio R. Randomised clinical trial: Calorie restriction regimen with tomato juice supplementation ameliorates oxidative stress and preserves a proper immune surveillance modulating mitochondrial bioenergetics of T-lymphocytes in obese children affected by non-alcoholic fatty liver disease (NAFLD). J Clin Med. 2020; 9:141.

https://doi.org/10.3390/jcm9010141

68. Gao Q, Zhong $C$, Zhou X, Chen R, Xiong $T$, Hong $M$, Li Q, Kong $M$, Han W, Sun G, Yang $X$, Yang $N$, Hao L. The association between intake of dietary lycopene and other carotenoids and gestational diabetes mellitus risk during mid-trimester: A cross-sectional study. Brit J Nutr. 2019; 121:1405-1412.

https://doi.org/10.1017/\$0007114519000606

69. Wiese M, Bashmakov Y, Chalyk N, Nielsen DS, Krych $\measuredangle$, Kot W, Klochkov V, Pristensky D, Bandaletova T, Chernyshova M, Kyle N, Petyaev I. Prebiotic effect of lycopene and dark chocolate on gut microbiome with systemic changes in liver metabolism, skeletal muscles and skin in moderately obese persons. Biomed Res Int. 2019; 2019:4625279. https://doi.org/10.1155/2019/4625279

70. Iriti $\mathrm{M}$, Varoni EM, Vitalini S. Melatonin in traditional Mediterranean diets. J Pineal Res. 2010; 49:101-105. https://doi.org/10.1111/j.1600-079X.2010.00777.x

71. Iriti M, Varoni EM. Melatonin in Mediterranean diet, a new perspective. J Sci Food Agr. 2015; 95:2355-2359. https://doi.org/10.1002/jsfa.7051

72. Vitalini S, Gardana C, Simonetti P, Fico G, Iriti M. Melatonin, melatonin isomers and stilbenes in Italian traditional grape products and their antiradical capacity. J Pineal Res. 2013; 54:322-333. https://doi.org/10.1111/jpi.12028

73. Salehi B, Sharopov F, Fokou PVT, Kobylinska A, Jonge LD, Tadio K, Sharifi-Rad J, Posmyk MM, Martorell M, Martins N, Iriti M. Melatonin in medicinal and food plants: Occurrence, bioavailability, and health potential for humans. Cells. 2019; 8:681. https://doi.org/10.3390/cells8070681

74. Art of Neapolitan 'Pizzaiuolo'. [https://ich.unesco.org/en/RL/art-of-neapolitan-pizzaiuolo00722]. Retrieved November 23, 2021. 